\title{
What Is Important For Continent Catheterizable Stomas: Angulations or Extension?
}

\author{
Marcelo L. Vilela, Geovanne S. Furtado, Ivan Koh, Luiz F. Poli-Figueiredo, Valdemar Ortiz, \\ Miguel Srougi, Antonio Macedo Jr
}

Department of Surgery, Divisions of Urology and Experimental Surgery, Federal University of Sao Paulo (UNIFESP), Sao Paulo, Brazil

\begin{abstract}
Objective: We developed an experimental ex-vivo model to define factors that may influence continence of catheterizable channels by urinary and colonic stomas based on the principle of imbrication of the outlet tube.

Materials and Methods: From 20 pigs, colon specimens with $25 \mathrm{~cm}$ length were obtained and a transverse flap with $3.0 \mathrm{~cm}$ length $\times 1.5 \mathrm{~cm}$ width in the average point of the intestine was tubulated to create an efferent tube. With the tube configured, it was embedded by 3 seromuscular stitches far $0.5 \mathrm{~cm}$ each other. A pressure study of both intra-luminal surface and channel was then conducted during the filling of the submerse piece with environmental air in a water container, to define the efferent channel continence. The study was repeated after the progressive release of suture stitches until only one stitch remains.

Results: Channel continence analyzed in each segment in three different valve length situations, making a total of 20

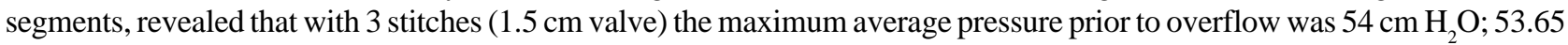
$\mathrm{cm} \mathrm{H}_{2} \mathrm{O}$ with 2 stitches ( $1.0 \mathrm{~cm}$ of valve), and $55.45 \mathrm{~cm} \mathrm{H}_{2} \mathrm{O}$ with only one stitch $(0.5 \mathrm{~cm}$ of valve), which are the same values. The record at the segment explosion pressure was $67.87 \mathrm{~cm} \mathrm{H}_{2} 0$.

Conclusion: The study showed that angulation of channel with colon, maintained by only one stitch $(0.5 \mathrm{~cm}$ imbrication $)$ was more important than a larger extension of the valve, represented by 3 suture stitches $(1.5 \mathrm{~cm}$ imbrication) in order to allow continence to the efferent channel.
\end{abstract}

Key words: urodynamics, urinary diversion, continent urinary reservoirs, fecal incontinence, animal experimentation, swine

Int Braz J Urol. 2007; 33: 254-63

\section{INTRODUCTION}

Mitrofanoff's principle is regarded as a routine procedure in pediatric urology and the appendix is the channel of choice for that purpose (1) being Monti's tubes a valid alternative (2).

Recently, our group published a technique of ileal catheterizable reservoir for bladder reconstruction, discharging the use of both appendix and Monti's tube, thereby simplifying the surgery strategy (3). Thereafter, the same principle has been applied to the left colon aiming to provide an ostomy for antegrade enemas in severe fecal incontinence as an alternative to MACE $(4,5)$. In both techniques, channel's continence mechanism is represented by imbrication of the efferent channel over seromuscular stitches either at the top of reservoir or at the colon. 
In order to understand best the functioning of this method of continence used in the above-mentioned techniques and attribute the importance of the extension of the necessary imbrication to produce continence, we developed an ex-vivo model in pig's colon segments with efferent channel under valve, aiming to check channel's continence by means of a pressure study (6).

\section{MATERIALS AND METHODS}

An experimental acute-type study model performed in Landrace pigs (16 females and 12 males) of approximately $20 \mathrm{~kg}$ weight was proposed. The animals were brought from the nursery to the laboratory 72 hours prior to the surgery and remained in a 12-hour fasting prior to surgical procedure.

The anesthetized animal was positioned in dorsal decubitus. After exposing the peritoneal cavity, a colectomy $50 \mathrm{~cm}$ far from the ileocaecal valve was performed.

A $25 \mathrm{~cm}$ length standard mold was used to define identical intestinal segments and the efferent channel in the medium point of the bowel. A $3 \mathrm{~cm}$ length $\times 1.5 \mathrm{~cm}$ width transverse flap from the anterolateral wall was tubulated with continuous

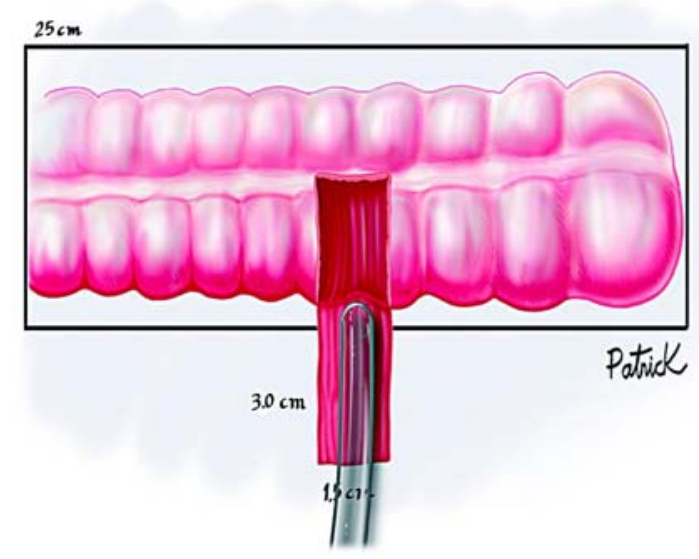

Figure 1-25 cm intestinal piece with overlapped mold. mononylon 6.0 suture, using a 12 French plastic catheter as mold (Figure-1). The defect created was likewise repaired by a total continuous anchored suture in the edges with the same thread (Figure-2). With the tube configured, the same was brought back to its bed for subsequent creation of a continence line. This continence valve was created by seromuscular stitches near the channel, aiming to promote channel imbrication in the intestinal bed. In the present experiment, it was defined that this suture should be made with three separated stitches with mononylon 6.0 thread from $0.5 \mathrm{~cm}$ of the channel's base with 1 $\mathrm{cm}$ of lateral spacing and distally advancing each stitch in $0.5 \mathrm{~cm}$ until completing the $1.5 \mathrm{~cm}$ length suture (Figure-3). At the distal end of this channel, a 12 French plastic catheter has been fixed, with minimum introduction, connected with a pressure transducer (P2). Two other catheters, of the same measure as previously mentioned, were also introduced in each end of the intestinal segment, occluded thereafter with $0.5 \mathrm{~cm}$ thick multifilament cotton thread tying. In one of the catheters, a piece with a sphygmomanometer

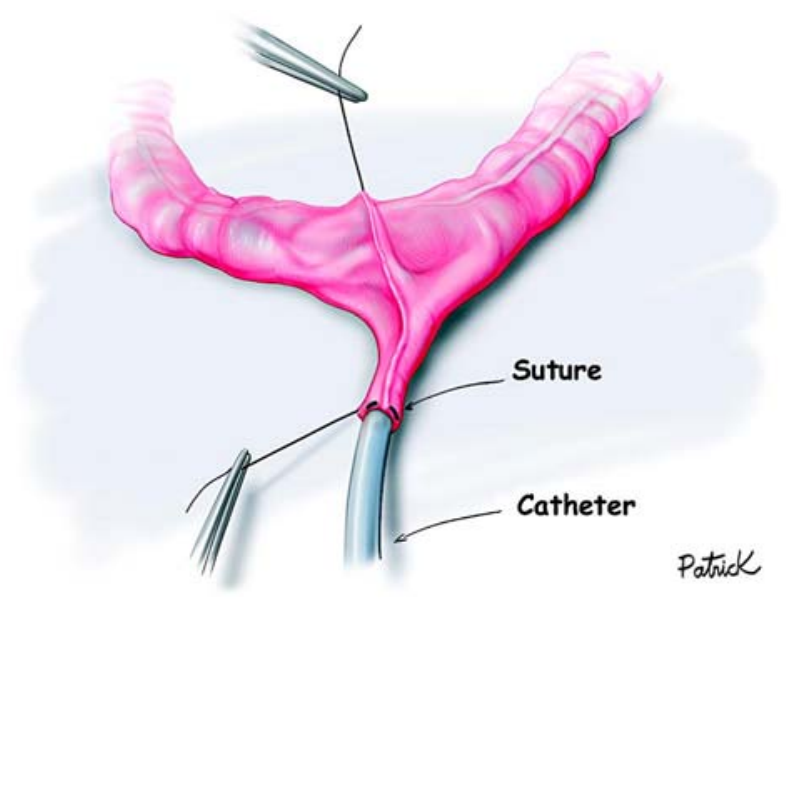

Figure 2 - Making of intestinal channel and repair of intestinal wall. 


\section{Experimental Catheterizable Stomas}

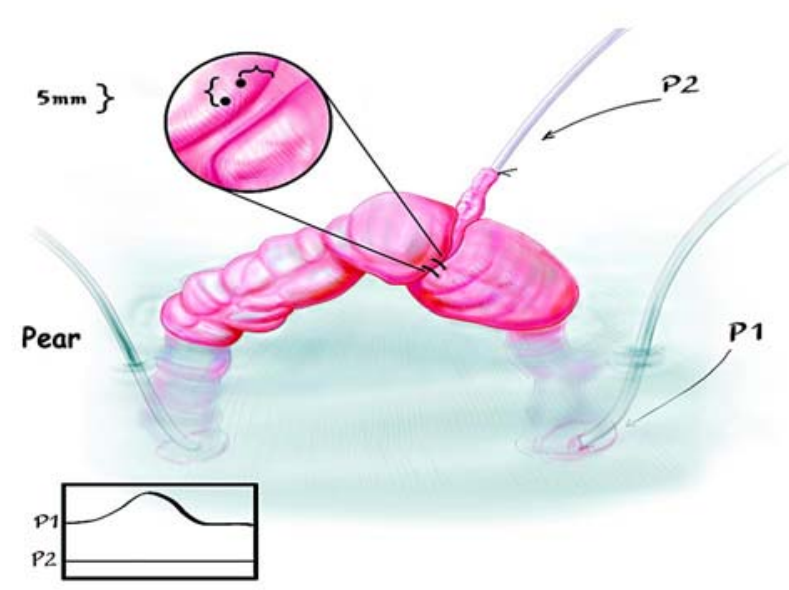

Figure 3 - Standardization of continence line distance of seromuscular stitches at the intestine.

insufflating mitten was used to insufflate air into the piece. The other was connected with a second pressure transducer $(\mathrm{P} 1)$ in order to record the pressure at the bowel lumen. After completion of this procedure, the recording of the data to evaluate effectiveness of the valve mechanism and channel's continence was initiated.

In the bowel segment, pressure measures through two catheters tied to the ends, namely: luminal pressure (P1) and channel pressure (P2) were defined. The piece was immersed in the $7.5 \mathrm{~L}$ flowing water container in order to remain immersed in water and three $500 \mathrm{~g}$ metallic weights were tied to the ends. A third catheter was connected with an insufflating mitten, to allow filling of the piece with environment air. Channel's continence was objectively studied in each intestinal piece through the pressure study of the reservoir.

Air filling in the piece was performed in a progressive manner, taking into account P1 (luminal pressure) and P2 (channel's pressure) records. Control of piece continence has also been visually evaluated, recognizing occasional air losses with bubbling in water container in such a way the author could find where the air was coming from. A loss of air through the channel would represent a valve failure and define the channel leak point pressure (Figure-4).
We defined 2 experiments to validate our data collection as follows:

A) Validation of P2 (channels' pressure) record. We selected 3 bowel segments in which the channel was maintained without valve and a reading of $\mathrm{P} 1$ and $\mathrm{P} 2$ records was performed in accordance with the experiment protocol. In the lack of a valve, there was the communication of the luminal surface of intestinal lug with the channel. Thus, we would reach similar pressure levels, which would validate $\mathrm{P} 2$ record.

B) Intestinal piece rupture pressure. We selected 8 intestinal segments, which were immersed in the reservoir without making the channel, just with intraluminar (P1) pressure, aiming to define bowel pressure of rupture or explosion pressure. Based on this result, we could define the approximate maximum limit of pressure when insufflating pieces of the main experiment.

Data collection methodology was performed so as to establish initial pressure records with the three stitches applied. Then, the most distal stitch was removed and the pressure measures repeated. The procedure was progressively repeated until the removal of the last stitch. This methodology allowed us to evaluate valve extension in channel continence.

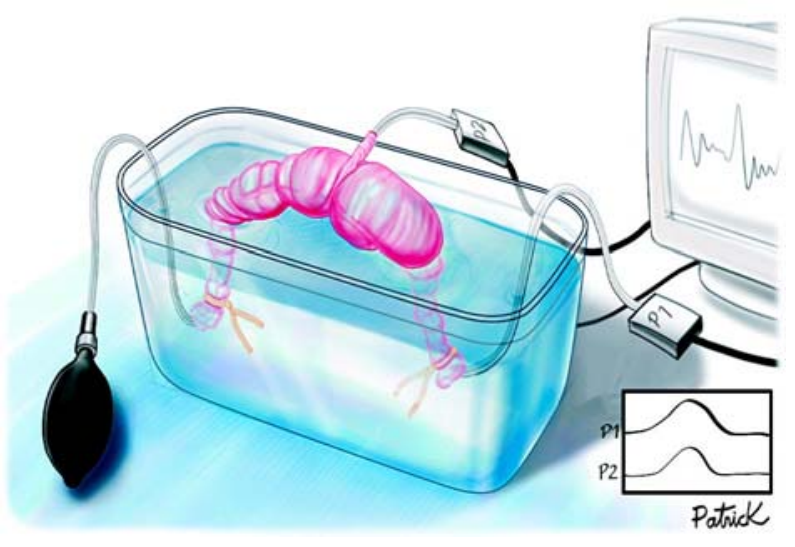

Figure 4 - Illustrative photo of the experiment showing arrangement of catheters and $P 1$ and $P 2$ transducers for demonstrating before immersion on the water and give the pressures. 


\section{RESULTS}

Results were reviewed in both analytical and descriptive manner, which are presented on tables and graphs.

Sub-experiment A (validation of P2): It was found that in 3 intestinal segments evaluated without making a valve, $\mathrm{P} 1$ and $\mathrm{P} 2$ records were identical, thereby confirming that channel pressure registered by $\mathrm{P} 2$ constituted an actual parameter with no methodology artifact (Figure-5).

Sub-experiment B (Intestinal piece rupture pressure). Values obtained in the evaluation of eight intestinal pieces showed that intestinal segment average explosion pressure was $67,875 \mathrm{~cm} \mathrm{H}_{2} \mathrm{O}$ (Table-1). It should be noted that the intestine rupture occurred always at the time of insertion of mesocolon vessels.

Channel continence analyzed in each segment in 3 different valve length situations, making a total of 20 segments showed that with 3 stitches $(1.5 \mathrm{~cm}$ of valve) the maximum average pressure checked was $54 \mathrm{~cm} \mathrm{H}_{2} \mathrm{O}$. With 2 stitches ( $1.0 \mathrm{~cm}$ of valve) the maximum average pressure checked was $53.65 \mathrm{~cm}$ $\mathrm{H}_{2} \mathrm{O}$, and with only one stitch $(0.5 \mathrm{~cm}$ of valve) the maximum pressure checked was $55.45 \mathrm{~cm} \mathrm{H}_{2} \mathrm{O}$ (Table-2).

The maximum pressure found represented the moment in which we observed the air loss (bubbling) at the suture line of the defect created by the intestinal piece. At no time, air loss by the channel was noted.

Table 1 - Intestinal pressure of rupture.

\begin{tabular}{cc}
\hline Intestinal Piece & Rupture Pressure $\left(\mathrm{cm} \mathrm{H}_{2} \mathrm{O}\right)$ \\
\hline 1 & 88 \\
2 & 73 \\
3 & 48 \\
4 & 67 \\
5 & 56 \\
6 & 45 \\
7 & 56 \\
8 & 110 \\
Average & 67.87 \\
\hline
\end{tabular}

P1 (luminal pressure) and P2 (channel pressure) analysis in a valveless situation (3 intestinal segments) revealed the total correspondence between the two records in the urodynamic study, thereby validating P2 measure. It can be noted that there is a parallelism among curves in the urodynamic ranging.

In the main experiment with piece filling, we noted the increase of $\mathrm{P} 1$ ranging without increasing $\mathrm{P} 2$, which characterizes the effectiveness of the valve mechanism of continence in an urodynamic viewpoint (Figure-6).

\section{COMMENTS}

Complications of continent catheterizable ostomies are well known but mainly they reflect stoma incontinence and stenosis. Schneider et al., 1974, in their experimental work with continent vesicostomy, related such types of complications (7). Mitrofanoff, in 1980, in his first clinical series published, showed $15 \%$ of ostomy-related complications that ended up motivating a surgical review (1). Malone, in 1995, showed a success rate of about $71 \%$ for MACE surgery and among the twenty-one children submitted to surgery, the most frequent complications were associated to ostomies, mainly stenosis (in five children) and incontinence (also in five children) (8).

Since 1998, our group has been successfully applying the technique of bladder augmentation with catheterizable channel made from a flap of the own ileal intestinal wall (3). This technique precludes the need of caecal appendix and the isolation of an ileum pediculate segment, as well as entero-anastomosis, as it happens in Monti's technique. Results are quite stimulating and similar to literature with low rates of complications. In a recent analysis of the fifty-four (54) initial cases, stoma-related complications were $7.4 \%$ and stenosis, also in $7.4 \%$ (9).

The idea of proposing such experiment was based on some doubts, which raised with the development of the efferent channel principle, since the literature has no objective data regarding channel length or the necessary extension of seromuscular imbrication, as well as the number of stitches to assure incontinence. We wanted to investigate exclusively 

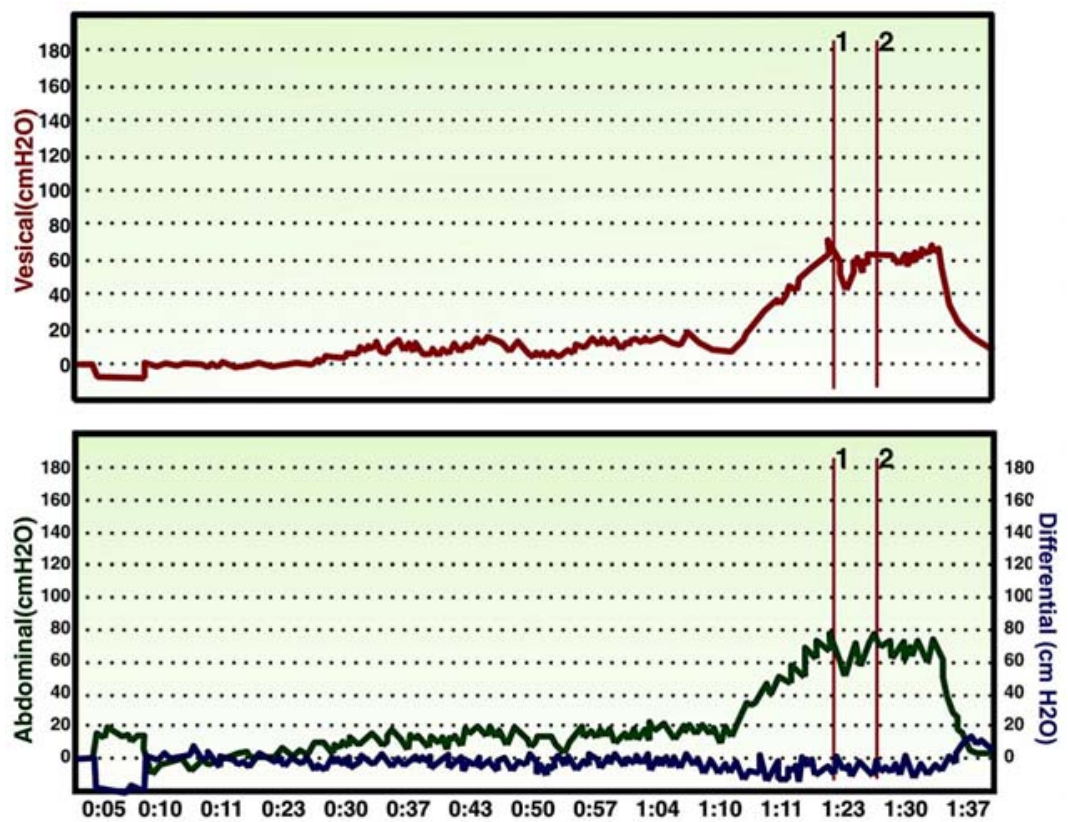

Figure 5 - Pressure curves of intestinal light ( $P 1$ - red ranging), channel (P2 - green ranging) and gradient pressure ( $P 3$ - purple ranging) showing parallelism in the lack of valve; thereby validating $P 2$ record.
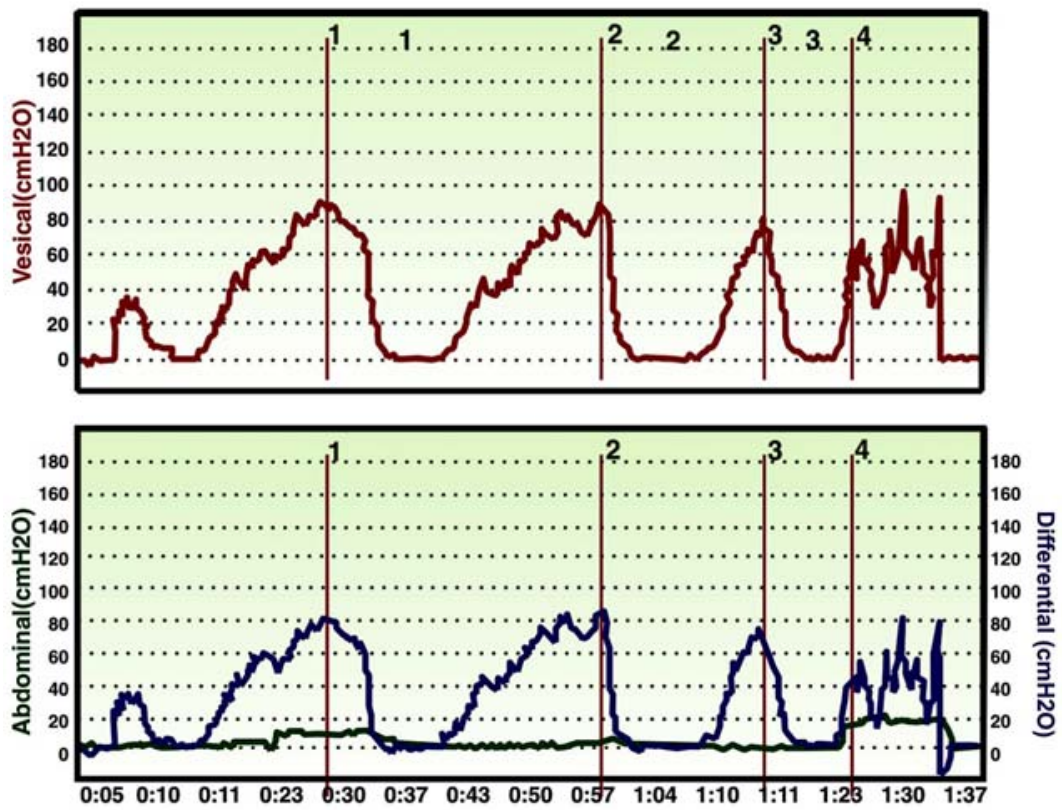

Figure 6 - Urodynamic apparatus pressure records demonstrating that, after making the valve, P1 (red ranging = intestinal pressure) and $P 2$ (green ranging = channel pressure) curves fail to present parallelism, and in cut 1 the valve has 3 stitches, in cut 2, 2 stitches and cut 3 only 1 stitch, maintaining the same effectiveness of the valve. The fourth test represent only the last stitch pressure for confirm the continence with 3 stitches. 
Table 2 - Maximum continence pressure of channels with 3, 2 and 1 imbrication sutures.

\begin{tabular}{lccc}
\hline Experimental Piece & Three Sutures & Two Sutures & One Suture \\
\hline 1 & 49 & 45 & 45 \\
2 & 50 & 50 & 49 \\
3 & 144 & 119 & 106 \\
4 & 83 & 88 & 78 \\
5 & 66 & 57 & 48 \\
6 & 50 & 50 & 69 \\
7 & 57 & 63 & 59 \\
8 & 55 & 56 & 55 \\
9 & 78 & 76 & 81 \\
10 & 46 & 45 & 46 \\
11 & 38 & 38 & 36 \\
12 & 38 & 36 & 42 \\
13 & 30 & 32 & 26 \\
14 & 48 & 45 & 48 \\
15 & 42 & 41 & 50 \\
16 & 44 & 43 & 46 \\
17 & 45 & 45 & 50 \\
18 & 48 & 48 & 48 \\
19 & 48 & 46 & 48 \\
20 & 51 & 50 & 50 \\
Average & $55.45 \mathrm{~cm}_{2} \mathrm{O}$ & $53.65 \mathrm{~cm}_{2} \mathrm{O}$ & $54 \mathrm{~cm}_{2} \mathrm{O}$ \\
\hline
\end{tabular}

the principle of imbrication of the tube, which we have been applying in our concept of neobladder and ACE.

Yue-Min Xu et al., 1999 (10), and Lampel et al., 1995 (11), used the urodynamic set to evaluate the continence of ileal and colonic channels, by utilizing a saline solution to fill the reservoir. In other experimental study, Koh et al., 1990 (12), showed that it is possible to introduce air into the intestine aiming to evaluate both distensibility and maintenance of intestinal wall integrity. We adopted this concept in our experiment because of its simplicity and assumed it could be feasible to evaluate the valve continence.

Based on this data, an original experimental model to evaluate continence of continent colonic channels was created. Loss characterization (bubbling) could be easily recognized, since the bowel was already immersed in a water container.
Standardization of plastic mold applied as a guide to section the efferent channel in the segment allowed us to reach uniformity both in the length of intestinal wall and in the measures of intestinal wall channel. The distance among continence seromuscular stitches, as well as the lateral spacing of both channel and intestinal lug was also standardized.

The animal model was chosen due to its medium size and a certain anatomic similarity of pig's large intestine with the human's.

In this study, we defined parameters used in the urodynamic study to define channel continence. The use of catheters respectively in the bowel lumen and in the channel lumen allowed us to confirm the pressure transmission between these two areas in the sub-experiment without valve making. The explosion pressure in eight segments, defined how much air could be insufflated into the intestinal segment without risk 
of explosion. It should be pointed out that bowel rupture occurred in the mesenteric face, at the time of immersion of vessels into walls, thereby corroborating the findings of work by Koh et al., 1990 (11).

Yue-Min Xu et al., in 1999 did an experimental work in dogs using urodynamic evaluation of catheterizable channels with valved mechanisms and valveless channels (9). Imbrication extension (continence line) at the abdominal wall in this work ranged from $2.5 \mathrm{~cm}$ to $4.0 \mathrm{~cm}$. The authors confirmed that the continence mechanism of the channels was effective and suggested that, as the pressure increases in the reservoir, the same pressure is transmitted to the channel, thereby defining the valvular mechanism. The authors concluded that both imbrication extension and channel size provide a protection mechanism for incontinence, since in abdominal wall tunnels with extension lower than $2.5 \mathrm{~cm}$ the leak pressure was lower. This study has the merit of being performed with animals with chronic segment. Lampel et al., in 1995, in a clinical evaluation of urinary diversion with Mainz Pouch's technique (ileocaecal reservoir), also using urodynamic apparatus, compared two types of channels in the colon and related that the maximum average contention pressure was $30 \mathrm{~cm} \mathrm{H}_{2} \mathrm{O}$ when the reservoir was empty, and $55 \mathrm{~cm} \mathrm{H}_{2} \mathrm{O}$ in full reservoirs. Imbrication extension (contention mechanism) was $3.8 \mathrm{~cm}$ (11).

Results noted in the present study are similar to those of literature regarding continence pressure, since while performing three contention stitches we found luminar pressures near the average explosion pressure of intestinal segments. However, limitations of this study should be pointed out. First, it treats an acute model, with ex-vivo intestinal segments. Suture line could jeopardize pressure measures if they would not be well done. Nevertheless, the use of proper threads (mononylon 6.0) and continuous suture allowed us to reasonably overcome this difficulty. Even so, the maximum continence point in all experiments was indeed the maximum resistance of this suture line, that is, the bubbling showed that losses did not occur by the channels but at the suture line. However, bubbling extension with an active valve occurred in high pressures and near bowel explosion pressure, which demonstrates effectiveness of the continence mechanism. We believe that in a chronic study, the maximum supported pressure could be even higher and we intend to subsequently perform it.

In analyzing the description of the surgical experiment, it can be noted that the model, even though ex-vivo, is effective to reproduce exactly the surgical technique we have been performing in the last six years for both urinary reservoirs and catheterizable colonic channels. We were able therefore to understand that according to our previous suspicions, angulation is more important than extension of the embedding stitches. We recognize however that the standard approach for Mitrofanoff principle (appendix/Yang-Monti tube) might have different resistance mechanisms and we respect the opinion of others in considering this strategy as first line treatment. We treat however, our patients differently in our department according to the above mentioned procedures.

Our study brought some interesting contributions to understand the continence mechanism of these catheterizable channels: A) Imbrication extension of the channel, as expected, does not seem to be a primordial factor to provide a good continence mechanism; B) A very important data in this experiment is that with only one stitch, that is, $0.5 \mathrm{~cm}$ of channel imbrication of the outlet tube, we already obtained the continence. These make us believe that channel angulation provided by this stitch is the main factor for the continence.

\section{CONCLUSION}

The effectiveness of a valvular mechanism by catheterizable channels tested in this experimental model through pressure records (urodynamic) was attested. Most important than valve extension, the angulation at the imbrication maintained for only one point $(0.5 \mathrm{~cm})$ was the most important factor for efferent channel continence, since the overflow pressure (bubbling) had no statistically significant difference for $0.5,1.0$ and $1.5 \mathrm{~cm}$ imbrication.

\section{CONFLICT OF INTEREST}

None declared. 


\section{REFERENCES}

1. Mitrofanoff P: Trans-appendicular continent cystostomy in the management of the neurogenic bladder. Chir Pediatr. 1980; 21: 297-305.

2. Monti PR, Lara RC, Dutra MA, de Carvalho JR: New techniques for construction of efferent conduits based on the Mitrofanoff principle. Urology. 1997; 49: 112-5.

3. Macedo A Jr, Srougi M: A continent catheterizable ileum-based reservoir. BJU Int. 2000; 85: 160-2.

4. Macedo A Jr: Re: Use of a colon based tubularized flap for an antegrade continence enema. J Urol. 2003; 170: 193; author reply 193.

5. Calado AA, Macedo A Jr, Barroso U Jr, Netto JM, Liguori R, Hachul M, et al.: The Macedo-Malone antegrade continence enema procedure: early experience. J Urol. 2005; 173: 1340-4.

6. Oliveira MV, Macedo JrA, Souza GF, Garrone GO, Srougi M: How continent are catheterizable urinary and colonic stomas? an ex-vivo experimental model. BJU Int. 2003; 91 Suppl 1: 5.
7. Schneider KM, Ewing RS, Signer RD: Continent vesicostomy. Urology. 1974; 3: 654-6.

8. Malone PS: The management of bowel problems in children with urological disease. Br J Urol. 1995; 76: 220-5.

9. Macedo JrA, Garrone GO, Júnior UOB, Srougi M: Continent catheterizable stomas: should we change? J Urol. 2003; 169 Suppl 4: 125.

10. Xu YM, Iizuka K, Kato H, Gu BJ, Igawa Y, Nishizawa O: Enhanced continent mechanism of tapered ileum by extramural support from pouch-abdominal wall: an experimental study in dogs. J Urol. 1999; 161: 706-11.

11. Lampel A, Hohenfellner M, Schultz-Lampel D, Thuroff JW: In situ tunneled bowel flap tubes: 2 new techniques of a continent outlet for Mainz pouch cutaneous diversion. J Urol. 1995; 153: 308-15.

12. Koh IH, Kim YR, Crotti PL, Stávale JN, Nigro AJ, Goldenberg S: Estudo comparativo de duas técnicas operatórias para o tratamento cirúrgico do apêndice vermiforme por secção e por invaginação. Estudo experimental em coelhos (Oryctolagus cuniculus). Acta Cir Bras. 1990; 5: 123-9.
Accepted after revision:

November 10, 2006

\author{
Correspondence address: \\ Dr. Marcelo Brandão Vilela \\ Rua Castro Alves, 218 \\ Campo Grande, MS, 79002-460, Brazil \\ Fax: + 556733218231 \\ E-mail:marcelo.vilela@sbu.org.br
}

\section{EDITORIAL COMMENT}

In this experimental study, the authors developed an ex-vivo animal model to investigate the factors that may influence continence of catheterizable conduits based on the principle of imbrication of the outlet tube. They compared whether angulation and extension of imbrication affected the continence mechanism. They found that angulation of channel with colon, maintained by only one stitch $(0.5 \mathrm{~cm}$ imbrication) was more important than a larger extension of the valve, represented by 3 suture stitches $(1.5 \mathrm{~cm}$ imbrication) in order to allow continence to the efferent channel.

This is a very well designed animal study to objectively show the effectiveness of imbrication, which 
is a frequently used technique to achieve the continence while creating catheterizable channels. As authors clearly demonstrated, the creation of angulation itself is more important than the length of the imbricated part of the conduit. Although, this is may not true when the conduit and the through, in which the conduit is placed, is in the same plane (no angulation at all) $(1,2)$. In this time, the length of the imbricated tunnel may become important to create an effective continence. Another point is an acute angulation may cause problems related with catheterization.

In standard technique, appendix or YangMonti tube is used to create a channel. If both of them are not available transverse flaps from ileum or colon can be used $(3,4)$. In this study, the authors showed the effectiveness of channels based on transverse colon flaps. In my opinion, appendix, if available, must be the first choice because of stronger muscle backing which affect long-term success rate regarding continence and ease of catheterization.

\section{REFERENCES}

1. Herndon CD, Cain MP, Casale AJ, Rink RC: The colon flap/extension Malone antegrade continence enema: an alternative to the Monti-Malone antegrade continence enema. J Urol. 2005; 174: 299-302.

2. Soygur T, Arikan N, Zumrutbas AE, Gulpinar O: Serosal lined extramural tunnel (Ghoneim) principle in the creation of a catheterizable channel in bladder augmentation. J Urol. 2005; 174: 696-9.

3. Macedo Jr A, Srougi M: A continent catheterizable ileum based reservoir. BJU Int. 2000; 85: 160-62.

4. Herndon CD, Cain MP, Casale AJ, Rink RC: The colon flap/extension Malone antegrade continence enema: an alternative to the Monti-Malone antegrade continence enema. J Urol. 2005; 174: 299-302.

Dr. Tarkan Soygur
Chief of Pediatric Urology
University of Ankara, School of Medicine
Ankara,Turkey
E-mail: soygur@medicine.ankara.edu.tr

well as defining one of the limitations of an ex vivo model by determining segment explosion pressure. It appears that intraluminal pressures remain constant between tunnel lengths of $0.5-1.5 \mathrm{~cm}$. This has potential clinical application as it seems that surgeons should strive to make a longer tunnel but feel somewhat comforted by the fact that the continence mechanism can potentially remain intact as long as 1 suture remains in place. Imbrication at the base of the channel maintains angulation and it would seem reasonable to assume that this is the most important suture from a technical standpoint, although in the current study, pressures were only measured by sequentially removing the distal sutures and not from the base out distally, so this assumption cannot be validated. 
The authors point out their limitations of a fresh suture line but are addressing this with a more chronic study.

This paper certainly contributes to our understanding of the contributing factors that will make this procedure successful in our patients. Construction of continent urinary stomas using the Mitrofanoff principle remains the preferred choice at our institution. Imbrication of the base of the appendix during an ACE procedure is dictated by surgeon preference, however, also depends upon the surgical approach taken with imbrication less likely during a laparoscopic procedure. No matter the technique chosen, the importance of meticulous attention to detail when constructing these channels cannot be overemphasized (3).

\section{EDITORIAL COMMENT}

Creation of continence mechanism is a mainstay in the armamentarium of pediatric urologists and reconstructive surgeons since it was originally described by Mitrofanoff in 1980. Since this publication, there was an increased interest in preserving the appendix for creating a stoma in a MACE procedure, for preferences of the surgeon, and at other times because the appendix was not available.

In this article, Vilela et al, developed an experimental ex-vivo model to define the factors that influenced continence of catheterizable stomas based on the principle of imbrication of the outlet. The authors should be congratulated because this research study

\section{REFERENCES}

1. Macedo A Jr., Srougi M: A continent catheterizable ileum-based reservoir. BJU Int. 2000; 85: 160-2.

2. Calado AA, Macedo A Jr., Barroso U Jr., Netto JM, Liguori R, Hachul M, ET AL.: Macedo-Malone antegrade continence enema procedure: early experience. J Urol. 2005; 173: 1340-4.

3. Adams MC, Joseph DB: Urinary Tract Reconstruction in Children. In: Wein AJ, Kavoussi LR, Novick AC, Partin AW, Peters CA (eds.), Campbell-Walsh Urology. Philadelphia, Saunders. 9th ed, chapter 124, 2007, p. 3656.

Dr. John C. Thomas

Division of Pediatric Urology

Monroe Carell Jr. Children's Hospital at Vanderbilt

Nashville, Tennessee, USA

E-mail:john.thomas@vanderbilt.edu

was very well conducted. The authors demonstrate the potential to achieve stoma continence rates with only one stitch, suggesting that the angulation and not the extension of the imbrication is the main factor for continence. This help to understand the continence mechanism and the extension of the necessary imbrication of the efferent channel over seromuscular stitches to produce continence.

As the authors pointed out there are several variations in surgeon's preferences when doing a catheterizable stoma. This article will help the surgeon, when performing an imbrication procedure to a catheterizable stoma, to better understand the physiologic process to gain continence.

Dr. Miguel Castellan Jackson Memorial Hospital and Miami Children's Hospital, University of Miami Miami, Florida, USA E-mail: miguel.castellan@excite.com 